\title{
Studies on the Virulence of Hospital Strains of Pseudomonas aeruginosa
}

\author{
BY KATHLEEN M. KLYHN AND R. H. GORRILL \\ Department of Bacteriology, Guy's Hospital Medical School, London, S.E.1
}

(Accepted for publication 17 December 1966)

\section{SUMMARY}

The virulence of 36 strains of Pseudomonas aeruginosa was studied by intravenous injection into mice; the strains were found to fall into three broad groups, of high, medium and low virulence. This difference could not be related to any biochemical property studied, pyocine type nor antibiotic sensitivity pattern. It was found that 24 of the 30 strains of the high and medium virulence group produced large colonies on agar while 5 of the 6 strains of the low virulence group produced small colonies when plated under similar conditions. To test this observation a further series was collected and the strains were allocated to the high or low virulence category on colonial appearance. Mouse challenge with these fresh strains showed that the prediction was accurate. The large colony type had a faster growth rate on agar and in broth than the small. When a strain was grown in agar it was found to be more virulent than when harvested from broth $(P=0.02-0.01)$. Chromatography studies on slime derived from all three categories showed that they were apparently chemically similar. The amount of slime produced by a standard number of bacteria was measured for agar and broth grown cultures. The yields for the two media were approximately the same with large-colony forms. Small-colony forms produced similar amounts to the large forms on plates, but up to 15 times as much when grown in broth.

The ability to kill mice was derived in part from early toxic death; the remainder died of renal disease. Study of the initiation of kidney infection showed that large-colony types were more successful in maintaining their numbers in the kidneys over the first $5 \mathrm{hr}$. Strains grown on nutrient agar did not give higher counts in the kidney than those from broth in the first $5 \mathrm{hr}$ but after $24 \mathrm{hr}$ they grew faster, infected more kidneys and killed more mice.

\section{INTRODUCTION}

The human pathogen Pseudomonas aeruginosa (pyocyanea) is found frequently in hospital-acquired infections (Darrell \& Wahba, 1964; Bassett, Thompson \& Page, 1965; Wahba, 1965). Certain sites such as the urinary tract and burnt skin are particularly susceptible, as are patients with lowered resistance and children. Pseudomonas aeruginosa infections are difficult to cure owing to their failure to respond to most antibiotic treatments. The epidemiology of $\boldsymbol{P}$. aeruginosa cross-infection has shown that organisms can survive in moist conditions even in the presence of some antiseptics (Rogers, 1960; Emmanouilidou-Arseni \& Kommentaleou, 1964; Ayliffe et al. 1965). Recent reports have indicated that this organism can survive and multiply in unexpected places such as jet fuel (Bushnell \& Hass, 1941; Edwards, 1965) and it has been found in this laboratory in the silicone fluid used as a syringe lubricant. In addition to being 
pathogenic for man $P$. aeruginosa is an insect pathogen (Angus, 1965) and a plant pathogen (Bullock, 1965). Members of the genus are known to be involved in plant disease (Paton, 1960) and to contribute to the spoilage of meat, poultry and eggs (Ayres, 1960).

Despite its importance as a human pathogen there is relatively little agreement as to the characters which confer virulence. To study this problem it was proposed to devise an experimental model in which virulence and a number of characters could be related. It is always difficult to produce a successful animal model of human disease but the following argument may be put forward.

Pseudomonas aeruginosa is found in human pyelonephritis (Seneca, Lattimer \& Peer, 1964; Ambrose \& Hill, 1965) and experimental murine pyelonephritis can be produced in the laboratory (Gorrill, 1965; Gorrill, Klyhn \& McNeil, 1966), hence experimental infection in mice would be not too far removed from the human disease pattern. Earlier work (Gorrill, 1952) had shown that strains derived from different sorts of lesions were efficient at producing mouse-kidney infection, so it would be possible to compare in this model a number of isolates made from a variety of hospital infections.

One of the fractions believed to be important in the virulence of Pseudomonas aeruginosa is the outer slime layer (Liu, Abe \& Bates, 1961; Liu \& Mercer, 1963; Callahan, Beyerlein \& Mull, 1964; Brown \& Lowbury, 1965). Much less often strains appear to be encapsulated and they too are virulent (Çetin, Töreci \& Auğ, 1965). In one strain isolated from a case of cystic fibrosis it was found that the mucoid fraction was different from that obtained from strains isolated from other conditions. Hence not only may slime be important in virulence but its composition may influence or be influenced by the type of disease produced (Doggett, Harrison \& Wallis, 1964; Doggett, Harrișon, Stillwell \& Wallis, 1965). It was proposed to investigate the relationship between mouse virulence and other characters of $P$. aeruginosa isolated from clinical cases with particular reference to the role of slime, and the amounts and composition of this fraction in different strains would be compared.

\section{METHODS}

Organisms. Pseudomonas aeruginosa strains were received from the Clinical Pathology Department, Guy's Hospital, derived from infected wounds, sputa, tracheal suckings and urines; 50 strains were initially collected. Later a further 40 were used to verify the findings on colony size and virulence. The cultures were maintained on meat digest agar slopes (Southern Group Laboratories, London), and the medium used throughout for culture unless otherwise stated.

Morphology. On isolation the colonial appearance, pigment production (Wahba \& Darrell, 1965) motility and Gram reaction were recorded. Capsule and slime stains were also made (Duguid, 1951; McKinney, 1953).

Biochemical reactions. The following tests were made; (a) oxidase by Kovacs method (1956); (b) fermentation versus oxidation of carbohydrates (Hugh \& Leifson, 1953); (c) gluconate test (Hayes, 1951); (d) growth at $37^{\circ}$ and $41^{\circ}$ (Hayes, 1951); (e) growth on $1 \%$ triphenyl tetrazolium chloride and $0.2 \%$ cadmium sulphate (Wahba, 1965); $(f)$ Wahba's modification (1965) of Oakley, Warrack \& van Heyningen (1946) test for collagenase; $(g)$ urease by Christensen's method (1946); $(h)$ haemolysis of horse blood was tested by growing the cultures on $5 \%$ horse blood agar plates; 
(i) antibiotic sensitivity patterns $3 \mathrm{hr}$ static cultures were used to flood plates of sensitivity test agar (Oxoid Ltd., London). Excess culture was removed and either Oxoid Multodisks (11-14D) or Evans Sentest high potency tablets applied. The results were read after overnight incubation at $37^{\circ}$.

Pyocine typing. A modification of the method of Darrell \& Wahba (1964) was used. The test strain was streaked across a 10 in. $(25.4 \mathrm{~cm}$.) plate of Tryptone Soya Agar (Oxoid) containing $5 \%(\mathrm{v} / \mathrm{v})$ horse blood and then incubated for $14 \mathrm{hr}$ at $32-34^{\circ}$. The bacteria were then killed with chloroform vapour and scraped off with a microscope slide. Narrow streaks of $4 \mathrm{hr}$ cultures of the 12 indicator strains were then printed on the plate at right angles to the test strain. After incubation for $8-18 \mathrm{hr}$ at $37^{\circ}$ the inhibition patterns were read. The indicator strains were printed on to the plate by using 12 stainless-steel blades held in a Perspex block; the blades were charged by dipping into 12 wells cut in a Perspex block $5 \times 3.5 \times 0.75$ in. $(12.7 \times 8.9 \times 1.9 \mathrm{~cm}$.). Each well contained one $4 \mathrm{hr}$ culture of an indicator strain. This machine, described by Wahba \& Lidwell (1963) was made in the workshop of Guy's Hospital Medical School.

Animal experiments. LD 50 values were obtained by the methods reported by Gorrill \& De Navasquez (1964) and Gorrill (1965), using 6 mice for each dose. The LD50 values were calculated by the method of Reed \& Muench (1938). Since cultures grown in broth are reported to contain little extracellular slime (Doggett et al. 1964; Liu et al. 1961) it was decided to prepare some strains for intravenous challenge from organisms grown on nutrient agar plates. Dilutions of Pseudomonas aeruginosa containing between 50-100 organisms were spread over meat digest agar plates and incubated overnight. Next morning the colonies were washed off with sterile normal saline.

In some experiments the number of bacteria found in the kidney at different times after injection was studied as described by Gorrill (1965).

Chromatography. Chromatography of sugars was done on the extracellular slime layer of the first 36 strains collected. This group included representatives of high, medium and low virulence. Slight modifications were made to the earlier description of this method (Doggett et al. 1964, 1965). Digest agar medium was used throughout, the organisms were washed off with distilled water and the slime separated by shaking the suspension with Ballotini beads for $10 \mathrm{~min}$. The extraction of the slime from the supernatant fluid and the preparation of samples for chromatography were as described by Doggett et al. (1964).

Cell-wall preparations were autolysed so that their sugars could be compared with those of the slime layer. The bacteria were harvested from digest agar plates, with distilled water, the slime layer removed and the bacteria washed by centrifugation with distilled water until the supernatant fluid was clear. The deposit of bacteria (the yield from a $10 \mathrm{in}$. $(25.4 \mathrm{~cm}$.) plate) was suspended in $10 \mathrm{ml}$. of boiling distilled water to inactivate any cell-wall-degrading enzymes and also to prevent the formation of an aerosol of living organisms later in the experiment (Salton, 1964). The killed bacteria were then treated with an M.S.E. (Spencer St., London) Ultrasonic Power unit at 1.5 A for $10 \mathrm{~min}$. using a 0.75 in. $(1.9 \mathrm{~cm}$.) probe. The cell-wall deposit was washed twice with $10 \mathrm{ml}$. distilled water and then treated in the same way as the slime fraction. In both cases the chromatograms were run for $16-17 \mathrm{hr}$, rather than the $20 \mathrm{hr}$ used by Doggett et al. (1964), since it was found that some of the components ran off the paper in the longer period. 
Slime precipitation. The slime material from several strains was extracted in the same way as described under chromatography techniques. It was collected from known numbers of broth-grown or nutrient agar-grown bacteria and then precipitated, dried overnight and weighed.

\section{RESULTS}

\section{Morphology}

Considering the initial 50 strains all were found to be motile and Gram-negative. The colonies produced pigment (pyocyanin) on one or more solid media. The majority of strains were of the S and SR types, only two being of $R$ type (Wahba, 1965). However, in our hands there were some differences from the classification of Wahba. The $S$ type was described as being $2-3 \mathrm{~mm}$. irregular shape, effuse elevation with a lobate edge. The SR were smaller, 1-2 mm. diam., circular, of convex elevation and entire edge. The $R$ type were 2-3 mm. diam., of irregular shape, with a raised centre and an undulate edge. When our $S$ strains were plated on digest medium agar to produce 20-60 colonies/plate, the colonies were 9-10 mm. diam. and the SR colonies 2-3 mm. None of the 50 primary isolates showed mucoid, gelatinous or dwarf forms, but on subculture some strains did dissociate (Zierdt \& Schmidt, 1964).

With all the strains tested it was noticed that when homogenates of infected kidneys were spread on digest agar the colonial type was always of the dwarf form. However, subculture from these colonies restored the original colonial appearance. Suspensions of liver and spleen and red blood cells also had this effect. Examination of this phenomenon yielded the following observations. The haemoglobin present in the organs appeared to be responsible for the inhibitory effect, which was bacteriostatic rather than bactericidal. Haematin did not have this effect, while serum and plasma annulled the inhibitory effect when excess of these materials was incorporated in the plates.

The effect of the haemoglobin was only seen when it was spread as a surface layer in contact with the dividing bacteria. Blood agar plates were not inhibitory. When the haemoglobin was spread $1 \mathrm{hr}$ or more before the plates were inoculated the inhibitory effect was enhanced. When plates containing a thick layer of agar (i.e. more than $1 \mathrm{~cm}$.) were used the inhibitory effect was less marked. Various chemicals $\left(\mathrm{MgSO}_{4}, \mathrm{MnSO}_{4}\right.$, $\mathrm{NaCl}$ and $\mathrm{FeSO}_{4}$ ) overcame the inhibitory effect to various degrees.

These observations, together, suggest the binding of a nutritional factor. This effect was only seen under a rather limited range of conditions.

By the capsule and slime stains used we were unable to show capsules in our 50 strains and there was doubt about the presence of a slime layer. The method of McKinny (1953) showed, with some strains, organisms held together in strands, possible bound with slime. Unfortunately the original dye used by McKinny was no longer available and the nearest substitute $(8 \mathrm{G} \times 300$ I.C.I.) had to be used.

\section{Biochemical reactions}

All strains were oxidase-positive, oxidized carbohydrates and gluconate and produced slime, grew at $37^{\circ}$ and $41^{\circ}$ and grew on media containing tetrazolium and cadmium sulphate. Of 50 strains 6 were collagenase-negative and 35 urease-negative; only 14 produced $\alpha$-haemolysin on horse blood agar. All strains were resistant to penicillin, erythromycin, oleandomycin and methicillin, and all were sensitive to 
colistin. The results were variable with streptomycin, tetracycline, chloramphenicol, sulphonamides and novobiocin.

\section{Pyocine typing}

The first 50 strains were distributed among 6 types: 17 in group A, 16 in group B, 8 in group D, 3 in group K, 2 in group F, 2 in group L, and 2 were untypeable.

\section{Animal experiments}

The first 36 strains of Pseudomonas aeruginosa were tested for virulence by intravenous challenge of mice with broth-grown cultures and the LD50 dose calculated from the deaths which occurred during the first 14 days. Twenty strains killed in doses between $4 \times 10^{6}$ and $2.8 \times 10^{7} ; 10$ strains in doses between $3 \times 10^{7}$ and $7 \times 10^{7} ; 6$ strains in doses between $1 \times 10^{8}$ and $4 \times 10^{8}$. These three groups were referred to as being of high, medium and low virulence. While this grouping is to some extent arbitrary, it was noticed that 24 out of 30 strains of the high and medium group had colonies of the ' $S$ ' type while with the low virulence group 5 out of 6 strains produced SR colonies. A further 40 strains of $P$. aeruginos $a$ were collected and plated to give optimum colony formation: 33 were ' $S$ ' type and 7 SR. Seven $S$ and 7 SR strains were taken and used for mouse challenge. Six of $\mathrm{S}$ strains were found to be of high to medium virulence, 6 of 7 SR strains were of low virulence. Hence it appears that it was possible to predict mouse virulence from colony appearance.

The growth rates of these two types were different in broth, the ' $S$ ' strains being the faster. These experiments were then repeated with nutrient agar-grown bacteria. At intervals after inoculation the plates were washed clear of bacteria and their numbers counted. The growth rates again were different, the $\mathrm{S}$ forms growing faster.

Of the 36 strains grown in broth and tested for mouse virulence the first 18 were then grown on nutrient agar plates, harvested and used for mouse challenge. The results are given in Table 1 where it will be seen that 16 strains killed mice with a dose of fewer bacteria derived from agar cultures; one strain was the same; and one strain more virulent when grown in broth. This latter strain was not consistent in colonial morphology, dissociating frequently. Taking all 18 strains and comparing the virulence by the ' $t$ ' test on the $\log$ values of the LD50 (Gorrill, 1963) $P$ was between 0.02 and 0.01 , suggesting a significant difference between the organisms grown in the two media.

When the fate of the bacteria which arrived at the kidney was studied it was found, as reported earlier (Gorrill et al. 1966), that there was a marked decrease in numbers from the initial implant. However, when the S and SR strains were compared it was found that the decrease was much greater with the SR form. It was not possible to detect any difference between the strains grown in broth or agar in the initial clearance period. However, after $24 \mathrm{hr}$ the number of nutrient agar-grown bacteria began to increase faster than with the broth-grown bacteria, and the former produced more infected kidneys and killed more mice. In view of the work which suggests that slime may be of importance in the virulence of Pseudomonas aeruginosa (Liu et al. 1961; Callahan et al. 1964) it was considered possible that the difference between brothgrown and nutrient agar-grown strains might be due to differences in the amount of slime material produced under the different cultural conditions. 


\section{Slime precipitation}

Sixteen of the 18 strains of Pseudomonas aeruginosa used for mouse challenge after harvesting from nutrient agar plates were taken and the amount of slime produced by $10^{10}$ bacteria harvested from nutrient agar was compared with the amount produced by a similar number of bacteria harvested from broth culture. With the S-type colonies an average broth culture yielded $9.4 \mathrm{mg}$. slime and nutrient agar $6.6 \mathrm{mg}$.; the SR-type

Table 1. The $\log _{10}$ LD50 values of 18 cultures of Pseudomonas aeruginosa (strains) grown in broth or nutrient agar, and results of the ' $t$ ' test: there were both ' $S$ ' and ' $S R$ ' colony types among the 18 strains.

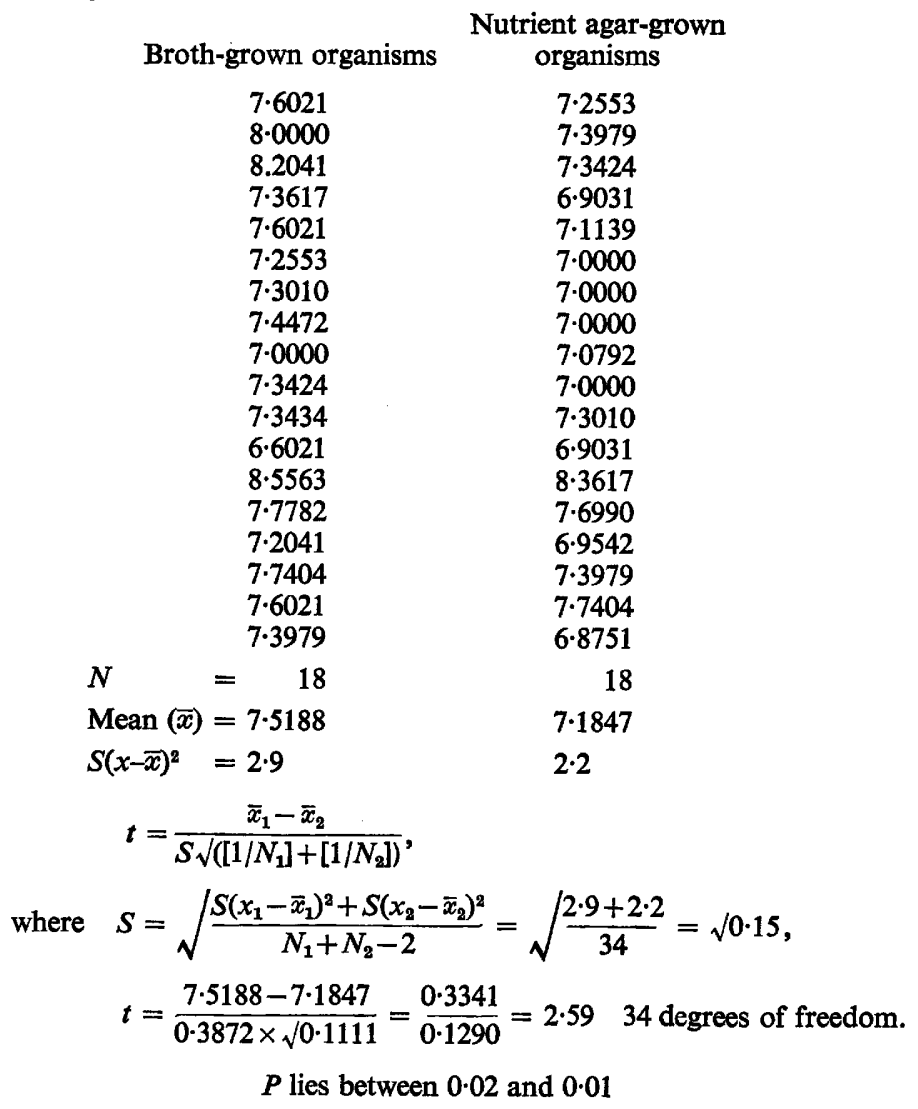

colonies broth yielded $74.4 \mathrm{mg}$. of slime and the agar-grown bacteria $5 \cdot 1 \mathrm{mg}$. The agar-grown bacteria were very similar but the results with broth cultures were unexpected: the SR-forms yielded about $8-10$ times as much slime as was expected. It appears either that the SR forms produced more slime, or that slime was much more easily detached from the bacteria during harvesting. 


\section{Chromatography}

The sugars detected in the extracellular slime of 36 strains of Pseudomonas aeruginosa in which the LD 50 values of broth-grown organisms had been measured were galactose, glucose, mannose and fucose, thus confirming the results of Doggett et al. (1965). Two other sugars were found which corresponded on chromatograms with controls of ribose and rhamnose; these two sugars were found when the chromatogram was run for only $17 \mathrm{hr}$. Two hexosamines were also found and provisionally identified as galactosamine and glucosamine. All the slime extracts were prepared in the same way, but there were differences in the intensity of the spot colours, possible indicating differences in quantity between strains. However these differences were shared equally between strains of high and low virulence. In the analysis of cell wall extracts of $P$. aeruginosa glucose, fucose and ribose were found; Salton (1964) reported glucose, fucose and rhamnose.

\section{DISCUSSION}

The mouse model for the study of the virulence of Pseudomonas aeruginosa suffers from the defect that many deaths are due to bacterial endotoxaemia. The stage of pyelonephritis and cystitis leading to renal failure which occurs later is more easily compared with the disease in man. Unfortunately it is not possible to separate the two effects and produce an infection in which death is due solely to renal failure. Despite its gloomy record $P$. aeruginosa infections in man are rarely rapidly fatal with endotoxaemia, and it would be much better for experimental work if one could produce an infection more like that seen in man. The latter part of the experimental infection with pus formation, abscesses and scarring is much more comparable. The main problem is whether one may take the LD50 dose calculated over the whole period as being a good guide to the severity of the pyelonephritis produced. This seems reasonable since the strains which killed in small doses with smaller doses produced a higher incidence of pyelonephritis than those which killed in large doses. The ability of $P$. aeruginosa to remain in the kidney and grow to large numbers is a good guide to a strain's ability to produce pyelonephritis.

After injection into mice the large-colony virulent type was cleared less efficiently than the small-colony type and grew more rapidly to destroy the kidney. The differences shown by statistical analysis between nutrient agar-grown and broth-grown organisms did not show in the early period, but after $24 \mathrm{hr}$ the difference became apparent, at first in the rate of increase in bacterial numbers, later in the number of kidneys infected and then destroyed, with subsequent death of the mouse.

Attempts to relate the differences in virulence between Pseudomonas aeruginosa strains, or between the same strain grown in broth or on nutrient agar, to slime formation, were unsuccessful. The composition of slime seemed the same for all strains tested and differences in intensity of the colour spots on the chromatogram were distributed at random amongst the high-, medium- and low-virulence strains. The estimates of the quantity of slime produced in broth and on agar which showed an excess production in broth-grown small-colony type (SR) organisms, the least virulent form tested, reflect the ease with which slime is detached from the SR bacteria, which would leave them deficient in slime. The other characters investigated were also unhelpful in predicting mouse virulence. However, there was a good correlation between 
colony size and virulence in mice as shown by LD50 values, renal clearance rates and incidence of pyelonephritis in the survivors. This appeared to reflect the difference in growth rate between large-colony and small-colony forms. It was not possible to show a difference in the growth rates of the same bacteria grown in broth and on nutrient agar, but as the animal experiments showed, this difference was not easy to demonstrate during a few hours and was probably within the limit of the error of counting.

The inhibitory effect of organ extracts and red blood cells on the colony size of Pseudomonas aeruginosa was apparently a local effect since it was lost on subculture into organ-free media. The findings seem to point to a nutritional effect, possibly the binding of an essential nutrient in the upper layer of the agar by the haemoglobin molecule.

We wish to thank the Medical Research Council and the Guy's Hospital Endowment Fund for grants to one of us (R.H.G.). Our thanks are due to Mr T. J. Southee and Mr R. Nash for technical assistance.

\section{REFERENCES}

Ambrose, S. S. \& HILL, J. H. (1965). Colony counts and chronic pyelonephritis. J. Urol. 94, 15.

ANGUs, T. A. (1965). Symposium on Microbial Insecticides. I. Bacterial pathogens of insects as microbial insecticides. Bact. Rev. 29, 364.

Ayliffe, G. A., Lowbury, E. J. L., Hamilton, J. G., Small, J. M., Asheshov, E. A. \& Parker, M. T. (1965). Hospital infection with Pseudomonas aeruginosa in neurosurgery. Lancet ii, 365.

AYRes, J. C. (1960). Relationship of organisms of the genus Pseudomonas to spoilage of meats, poultry and eggs, J. appl. Bact. 23, 533 .

BassetT, D. C. J., Thompson, S. A. S. \& PAge, B. (1965). Neonatal infections with Pseudomonas aeruginosa associated with contaminated resuscitation equipment. Lancet. i, 781.

BRowN, V.I. \& LowBURY, E. J. L. (1965). Use of an improved cetrimide agar medium and other culture methods for Pseudomonas aeruginosa. J. clin. Path. 18, 752.

BULLOCK, G. L. (1965). Characteristics and pathogenicity of a capsulated pseudomonad isolated from goldfish. Appl. Microbiol. 13, 89.

BushneLl, L. D. \& HASS, H. F. (1941). The utilization of certain hydro carbons by microorganisms. J. Bact. 41, 653.

Callahan, W. S., Beyerlein, B. \& Mull, J. D. (1964). Toxicity of Pseudomonas aeruginosa slime. J. Bact. 88, 805.

ÇETIN, E. T., TÖRECI, K. \& AuĞ, Ö. (1965). Encapsulated Pseudomonas aeruginosa (Pseudomonas aeruginosa mucosa) strains. J. Bact. 89, 1432.

CHRISTENSEN, W. B. (1946). Urea decomposition as a means of differentiating Proteus and Paracolon cultures from each other and from Salmonella and Shigella types. J. Bact. 52, 461.

DARReLL, J. H. \& WAHBA, A. H. (1964). Pyocine typing of hospital strains of Pseudomonas pyocyanea. J. clin. Path. 17, 236.

DogGetT, R. G., Harrison, G. M. \& Wallis, E. S. (1964). Comparison of some properties of Pseudomonas aeruginosa isolated from infections in persons with and without cystic fibrosis. J. Bact. 87, 427.

Doggett, R. G., Harrison, G. M., Stillwell, R. N. \& Wallis, E. S. (1965). Enzymic action on the capsular material produced by Pseudomonas aeruginosa of cystic fibrosis origin. J. Bact. 89, 476.

Duguin, J. P. (1951). The demonstration of bacterial capsules and slime. J. Path. Bact. 63, 673.

EDWARDS, P. (1965). Selection of test organisms for use in evaluating microbial inhibitors in fuelwater systems. Appl. Microbiol. 13, 823.

EMMANOUILIDOU-ARSENI, A. \& KOMMENTAKou, I. (1964). Viability of Pseudomonas aeruginosa. J. Bact. $87,1253$.

GoRRILL, R. H. (1952). Bacterial localisation in the kidney with particular reference to Pseudomonas pyocyanea. J. Path. Bact. 64, 857.

GORRILL, R. H. (1963). Staphylococcal infection in the mouse II. Variation in intracerebral virulence of a single strain of staphylococcus. Br. J. exp. Path. 44, 497. 
Gorrill, R. H. (1965). The fate of Pseudomonas aeruginosa, Proteus mirabilis and Escherichia coli in the mouse kidney. J. Path. Bact. 89, 81.

GoRrill, R. H. \& DE NAvasquez, S. J. (1964). Experimental pyelonephritis in the mouse produced by Escherichia coli, Pseudomonas aeruginosa and Proteus mirabilis. J. Path. Bact. 87, 79.

GorRILL, R. H., KLYHN, K. M. \& MCNeIL, E. M. (1966). The problem of the initiation of infection in the kidney following intravenous injection of bacteria. J. Path. Bact. 91, 157.

HAYES, W. C. (1951). Pseudomonas aeruginosa characterisation and identification. J. gen. Microbiol. 5, 939.

Hugh, R. \& LeIFson, E. (1953). The taxonomic significance of fermentation versus oxidative metabolism of carbohydrates by various Gram-negative bacteria. J. Bact. 66, 24.

Kovacs, N. (1956). Identification of Pseudomonas pyocyanea by the oxidase reaction. Nature, Lond. 178, 703.

LIU, P. V. \& Mercer, C. B. (1963). Growth, toxigenicity and virulence of Pseudomonas aeruginosa. J. Hyg., Camb. 61, 485.

LiU, P. V., ABE, Y. \& BATes, J. L. (1961). The roles of various fractions of Pseudomonas aeruginosa in its pathogenesis. J. infect. Dis. 108, 218.

MCKINNY, R. E. (1953). Staining bacterial polysaccharides. J. Bact. 66, 453.

OAKley, C. L., Warrack, G. H. \& van Heyningen, W. E. (1946). The collagenase (K toxin) of Clostridium welchii type A. J. Path. Bact. 48, 229.

Paton, A. M. (1960). The role of Pseudomonas in plant disease. J. appl. Bact. 23, 526.

REED, L. J. \& MUENCH, H. (1938). A simple method for estimating fifty per cent end points. Am. J. Hyg. 27, 493.

Rogers, K. B. (1960). Pseudomonas infections in a children's hospital. J. appl. Bact. $23,533$.

Salton, M. R. J. (1964). The Bacterial Cell Wall. Amsterdam: Elsevier Publishing Company.

SenteA, H., LAtTimer, J. K. \& Peer, P. (1964). The relationship among normal intestinal flora, kidney infections and kidney stones. J. Urol. 92, 603.

WaHBA, A. H. (1965). Hospital infection with Pseudomonas pyocyanea. An investigation by a combined pyocine and serological typing method. Br. med. J. i. 86.

WaHBa, A. H. \& DarRell, J. H. (1965). The identification of atypical strains of Pseudomonas aeruginosa. J. gen. Microbiol. 38, 329.

WAHBA, A. H. \& Lidwell, O. M. (1963). A simple apparatus for colicine typing. J. appl. Bact. $26,246$.

ZIERDT, C. H. \& SCHMIDT, P. J. (1964). Dissociation in Pseudomonas aeruginosa. J. Bact. 87, 1003. 